\title{
PROJETO TERAPÊUTICO SINGULAR NA PRODUÇÃO DO CUIDADO INTEGRAL: UMA CONSTRUÇÃO COLETIVA ${ }^{1}$
}

\author{
Diego Muniz Pinto², Maria Salete Bessa Jorge 3 , Antonio Germane Alves Pinto ${ }^{4}$, Mardênia Gomes Ferreira \\ Vasconcelos $^{5}$, Cinthia Mendonça Cavalcante ${ }^{6}$, Ana Zaiz Teixera Flores ${ }^{7}$, Aristides Saboia de Andrade
}

\begin{abstract}
${ }^{1}$ Recorte do Projeto - Organização das práticas de saúde mental no ceará na produção do cuidado integral: dilemas e desafios, financiado pela Fundação Cearense de Apoio ao Desenvolvimento Científico e Tecnológico (FUNCAP) e Ministério da Saúde. ${ }^{2}$ Discente do Curso de Mestrado Acadêmico Cuidados Clínicos em Saúde e Enfermagem da Universidade Estadual do Ceará (UECE). Bolsista da FUNCAP. Ceará, Brasil. E-mail: diegomupi@yahoo.com.br

${ }^{3}$ Doutora em Enfermagem. Professora Titular da UECE. Docente dos Cursos de Mestrado Acadêmico Cuidados Clínicos em Saúde e Enfermagem e Mestrado Acadêmico em Saúde Pública da UECE. Pesquisadora CNPq. E-mail: masabejo@uece.br

${ }^{4}$ Doutorando em Saúde Coletiva do Programa Associação Ampla de Instituições de Ensino Superior (AAIES) da UECE, Universidade Federal do Ceará (UFC) e Universidade de Fortaleza (UNIFOR). Professor Assistente da Universidade Regional do Cariri. Ceará, Brasil. E-mail: germanepinto@hotmail.com

${ }^{5}$ Discente do Curso de Mestrado Acadêmico em Saúde Pública da UECE. Bolsista CAPES. Ceará, Brasil. E-mail: mardeniagomes@ yahoo.com.br

${ }^{6}$ Doutorando em Saúde Coletiva do AAIES UECE/UFC/UNIFOR. Bolsista CAPES. Ceará, Brasil. E-mail: fcinthia@hotmail.com

${ }^{7}$ Mestre em Cuidados Clínicos em Saúde e Enfermagem. Ceará, Brasil. E-mail: anazaizflores@hotmail.com

${ }^{8}$ Acadêmico do Curso de Graduação em Medicina da UECE. Bolsista FUNCAP. Ceará, Brasil. E-mail: tidesaboia_andrade@ hotmail.com
\end{abstract}

\begin{abstract}
RESUMO: A construção de um projeto terapêutico singular pressupõe a participação coletiva e uma concepção de sujeito que contemple os aspectos biopsicossocial, espiritual e cultural. Objetivamos compreender como se dá a construção do projeto terapêutico de usuários no Centro de Atenção Psicossocial de Sobral-CE. Utilizamos a metodologia de natureza qualitativa, dentro de uma perspectiva crítica e reflexiva. O cenário foi o Centro de Atenção Psicossocial Geral de Sobral-CE, com 11 trabalhadores de saúde mental, cinco familiares e sete usuários. As técnicas de busca de informações selecionadas foram as seguintes: entrevista semiestruturada, grupo focal e observação sistemática. A análise do material empírico fundamentou-se na compreensão dos discursos fortalecidos pelo Fluxograma analisador do modelo de atenção de um serviço de saúde. Percebemos, então, que a construção do projeto terapêutico se dá com base nas necessidades de saúde de cada usuário, mediante um esforço mútuo entre trabalhador/usuário/família, com o intuito de promover saúde mental.
\end{abstract} DESCRITORES: Saúde mental. Assistência integral à saúde. Serviços de saúde mental.

\section{INDIVIDUAL THERAPEUTIC PROJECT IN AN INTEGRAL PRODUCTION OF CARE: A COLLECTIVE CONSTRUCTION}

\begin{abstract}
The construction of an individualized therapeutic project requires collective participation and a conception of the subject that contemplates bio-psychosocial, spiritual, and cultural aspects. The aim of this study was to better comprehend how therapeutic projects are constructed at the Psychosocial Care Center in Sobral, CE, Brazil. A qualitative research method was used within a critical and reflexive perspective. Eleven mental health workers, five members of the patients' families, and seven patients participated in the study carried out at the Psychosocial Care Center in Sobral, CE, Brazil. Data was collected through semi-structured interviews, focus groups, and systematic observation. Data was analyzed based on Merhy's analytic flowchart. Through this study, we perceived that therapeutic projects are constructed based on each individual's needs through mutual effort from workers/patient/family, with the purpose of promoting mental health.
\end{abstract}

DESCRIPTORS: Mental health. Comprehensive health care. Mental health services.

\section{PROYECTO TERAPÉUTICO INDIVIDUAL EN LA PRODUCCIÓN DEL CUIDADO INTEGRAL: UNA CONSTRUCCIÓN COLECTIVA}

\begin{abstract}
RESUMEN: La construcción de un proyecto terapéutico individual tiene como propuesta la participación colectiva y una concepción del sujeto en la que se consideran los aspectos biopsicosocial, espiritual y cultural, con el objetivo de entender cómo se construye el proyecto terapéutico en el Centro de Atención Psicosocial de Sobral-CE. El enfoque metodológico es de carácter cualitativo, crítico y reflexivo. El estudio se llevó a cabo en el Centro de Atención Psicosocial General de Sobral, con once trabajadores de salud mental, cinco familiares y siete usuarios. Las técnicas seleccionadas para la búsqueda de informaciones son las siguientes: entrevista semiestructurada, grupo focal y observación sistemática. El análisis del material empírico se basó en la comprensión de los discursos, fortalecido por el diagrama de flujo con el que se analiza el modelo de atención de un servicio de salud. Por lo tanto, percibimos que la construcción del proyecto terapéutico es basado en las necesidades de salud de cada usuario, a través de un esfuerzo de colaboración entre los trabajadores, los usuarios y la familia con el objetivo de promover la salud mental.
\end{abstract}

DESCRIPTORES: Salud mental. Atención integral de salud. Servicios de salud mental. 


\section{INTRODUÇÃO}

Tradicionalmente, a terapêutica utilizada com o paciente psiquiátrico não o considerava como sujeito ativo do seu tratamento, não envolvia sua família e não valorizava sua história, sua cultura, sua vida cotidiana e sua qualidade de vida. O principal foco de atenção era a doença. ${ }^{1}$

Com o movimento antimanicomial e com a desospitalização surgiram novos serviços de saúde mental, denominados de Centros de Atenção Psicossocial (CAPSs) e Hospitais-Dia. Tais serviços representam estruturas intermediárias entre a internação integral e a vida comunitária; são norteados pelos projetos da reforma psiquiátrica, os quais vêm sendo implementados em grande parte dos estados brasileiros. ${ }^{2}$ As modalidades de atendimento, no CAPS constituem um universo de prática destinado a dar suporte ao paciente em crise, envolvendo não só o tratamento clínico, mas uma compreensão da situação que o circunda, com intervenções cujo objetivo é assegurar sua reinserção no contexto social e familiar. ${ }^{3}$ Assim, propõe-se um cuidado que tem como premissas a integralidade da atenção e a humanização da assistência.

A problemática discutida na humanização não se restringe ao plano das relações pessoais entre terapeutas e pacientes, embora chegue até ele. Não se detém em rearranjos técnicos ou gerenciais das instituições, embora dependa deles. Trata-se de um projeto existencial de caráter político, trata-se de uma proposta para a "polis". ${ }^{4}$

O modelo de atenção psicossocial tem como características a valorização do saber e das opiniões dos usuários/famílias na construção do projeto terapêutico. Então, a terapêutica não se restringirá, em consequência, somente a fármacos e a cirurgia; há mais recursos terapêuticos do que esses, como, por exemplo, valorizar o poder terapêutico da escuta e da palavra, o poder da educação em saúde e do apoio psicossocial. ${ }^{5}$

Portanto, o projeto terapêutico incorpora a noção interdisciplinar que recolhe a contribuição de várias especialidades e de distintas profissões. Assim, depois de uma avaliação compartilhada sobre as condições do usuário, são acordados procedimentos a cargo de diversos membros da equipe multiprofissional, denominada equipe de referência. ${ }^{6}$ Ademais, como indica o termo "projeto", trata-se de uma discussão prospectiva e não retrospectiva, conforme acontecia tradicionalmente na discussão de casos em medicina. ${ }^{5}$
Assim, as equipes de referência empreendem a construção de responsabilidade singular e de vínculo estável entre equipe de saúde e usuário/ família. Cada profissional de referência terá o encargo de acompanhar as pessoas ao longo de todo seu tratamento naquela organização, providenciando a intervenção de outros profissionais ou serviços de apoio consoante necessário e, finalmente, assegurando sua alta e continuidade de acompanhamento em outra instância do sistema. ${ }^{5}$

Nesse sentido, a dimensão singular é, pois, a essência do projeto terapêutico. É o locus onde se inscreve a concepção de ser humano que determina a ação de saúde oferecida para alcançar o objetivo de criar produtos de saúde: cuidar, melhorar a qualidade de vida dos usuários, ampliar o entendimento e a apropriação do processo saúde-doença, entre outros. ${ }^{7}$

O cotidiano do cuidado em saúde mental envolve as relações entre trabalhadores e gestores da saúde, usuários, familiares e comunidade. Portanto, diante desse prisma, o artigo tem por objetivo analisar a construção do projeto terapêutico de usuários no Centro de Atenção Psicossocial de Sobral-CE.

\section{METODOLOGIA}

Pesquisa qualitativa, dentro de uma perspectiva crítica e reflexiva. Tal metodologia é adequada para a análise do fenômeno social investigado e sua interface com o campo da saúde mental. Nesta abordagem teórico-metodológica, pode-se dimensionar a compreensão dos significados, dos sentidos, das intencionalidades e das questões subjetivas inerentes aos atos, às atitudes, às relações e às estruturas sociais. ${ }^{8-9}$

Como local da pesquisa optamos pelo Centro de Atenção Psicossocial do Município de Sobral, Estado do Ceará, Brasil, um dos serviços substitutivos da Rede de Atenção Integral à Saúde Mental (RAISM) da cidade escolhida, como campo empírico.

Os sujeitos da pesquisa foram 27 pessoas distribuídas em quatro grupos: Grupo I - trabalhadores de saúde mental (oito); Grupo II - usuários (sete); Grupo III - familiares dos usuários (cinco) e Grupo focal (sete) dos trabalhadores de saúde mental. Como critério de inclusão, os usuários e familiares que participaram do estudo deveriam estar há pelo menos seis meses no CAPS e aceitar participar da pesquisa. Em relação aos trabalhadores de saúde mental, foram inclusos todos aqueles 
que tinham pelo menos um ano de permanência no serviço e que concordaram em fazer parte do estudo. Nesse sentido, todos os sujeitos acordaram suas participações mediante apresentação e assinatura do termo de consentimento livre e esclarecido.

Adotamos a amostragem intencional definida pela saturação teórica, a qual interrompe a captação de novos participantes, fundamentada na redundância e convergência de sentido e significado obtido durante a coleta e análise dos dados. ${ }^{10}$

Para a coleta das informações utilizamos as seguintes técnicas: entrevista semiestruturada, grupo focal e observação sistemática. O processo de coleta de dados aconteceu em cinco etapas: aproximação com o campo e os sujeitos; pactuação com os participantes da pesquisa; integração com as atividades do cotidiano da RAISM; aplicação das técnicas; e discussão sobre as evidências com os grupos representativos do estudo.

A pesquisa é um recorte do projeto "Organização das Práticas de Saúde Mental no Ceará na Produção do Cuidado Integral: dilemas e desafios", com registro na FUNCAP/MS pelo ${ }^{\circ}$ 15500/2004 e aprovado pelo Comitê de Ética em Pesquisa da Universidade Estadual do Ceará, sob protocolo $\mathrm{n}^{\circ} 0631536-6$, respeitando os princípios éticos e legais na pesquisa com seres humanos. ${ }^{11}$

Para o melhor entendimento do objeto de estudo, a análise do material empírico baseou-se na hermenêutica crítica, na qual o fundamento de análise é a práxis social na perspectiva crítico-analítica. Os passos operacionais foram: ordenação dos dados, classificação dos dados, e, por fim, a análise final dos dados. ${ }^{8-9}$

Em complementação à análise do material coletado, utilizamos o "fluxograma analisador do modelo de atenção de um serviço de saúde"12, o qual propiciou um confronto entre os dados obtidos pelas entrevistas e o observado na prática cotidiana desse serviço de saúde. Para melhor entendimento do processo, analisamos a construção de dois projetos terapêuticos: o de um usuário que já faz acompanhamento no CAPS e o de um usuário que estava pela primeira vez no serviço; observamos desde a sua entrada na RAISM, a construção do seu projeto terapêutico e a sua possível saída da rede.

Os resultados se conformam na configuração analítica da compreensão do objeto de estudo, dispostos em discursos e observações, constituindo o entendimento temático das categorias "Projeto terapêutico e sua construção coletiva: trabalhador de saúde/usuário/família", "Fluxos e itinerários terapêuticos no CAPS" e "Construção do projeto terapêutico compartilhado, integral e singular".

\section{RESULTADOS E DISCUSSÃO}

A análise do material empírico possibilitou uma aproximação com o objeto de estudo e revelou que o projeto terapêutico se dá com base nas necessidades de saúde de cada usuário, mediante um esforço mútuo entre trabalhador/usuário/família com o intuito de promover saúde mental. Desse modo, para melhor compreensão dessa relação e construção coletiva apresentamos a análise dos seus componentes, bem como conteúdos explícitos, contradições, divergências e convergências a partir de três categorias temáticas, entre elas: Projeto terapêutico e sua construção coletiva: trabalhador de saúde/usuário/família, Fluxos e itinerários terapêuticos no CAPS e Construção do projeto terapêutico compartilhado, integral e singular.

\section{Projeto terapêutico e sua construção coletiva: trabalhador de saúde/usuário/família}

No processo de cuidar em saúde mental no CAPS os sujeitos interagem a todo momento em fluxos, encontros e atividades condizentes com a demanda de atendimento e a proposta terapêutica operacionalizada no cotidiano. Em análise, evidenciam-se as entradas e as saídas do usuário no itinerário pela busca da resolução de seus problemas e necessidades.

Mensalmente, o Centro de Atenção Psicossocial atende uma média de 470 pessoas, entre procedimentos intensivos, semi-intensivos e não-intensivos. Essa classificação é organizada com base no tempo de permanência do usuário no CAPS. Assim, os procedimentos intensivos são destinados àqueles com permanência de continuidade diária no serviço. Já os procedimentos semi-intensivos e não-intensivos fundamentam os projetos dos sujeitos que necessitam estar semanalmente no CAPS, seja de forma intercalada ou não. A demanda dos transtornos evidencia os casos moderados e graves de psicose, transtornos do humor e esquizofrenia.

Como previsto, a dinâmica de funcionamento do serviço prioriza o trabalho em rede, ou seja, concebe a atenção integral em saúde mental por meio de uma gestão participativa. Esta é efetivada em reuniões para discussão do processo de trabalho, comunicação ampla dos trabalhadores entre si e também a inserção do usuário/família com suas singularidades na construção do projeto terapêutico. 


\section{Fluxos e itinerários terapêuticos no CAPS}

A cartografia do projeto terapêutico dos usuários do CAPS é mostrada nos dois fluxogramas analisadores, apresentados a seguir. No primeiro fluxograma descrito na figura 1, visualizamos a construção do projeto terapêutico do usuário que tem acesso pela primeira vez ao serviço, e no segundo fluxograma, representado pela figura 2, descrevemos a (re)construção do projeto terapêutico do usuário que já é acompanhado no serviço.

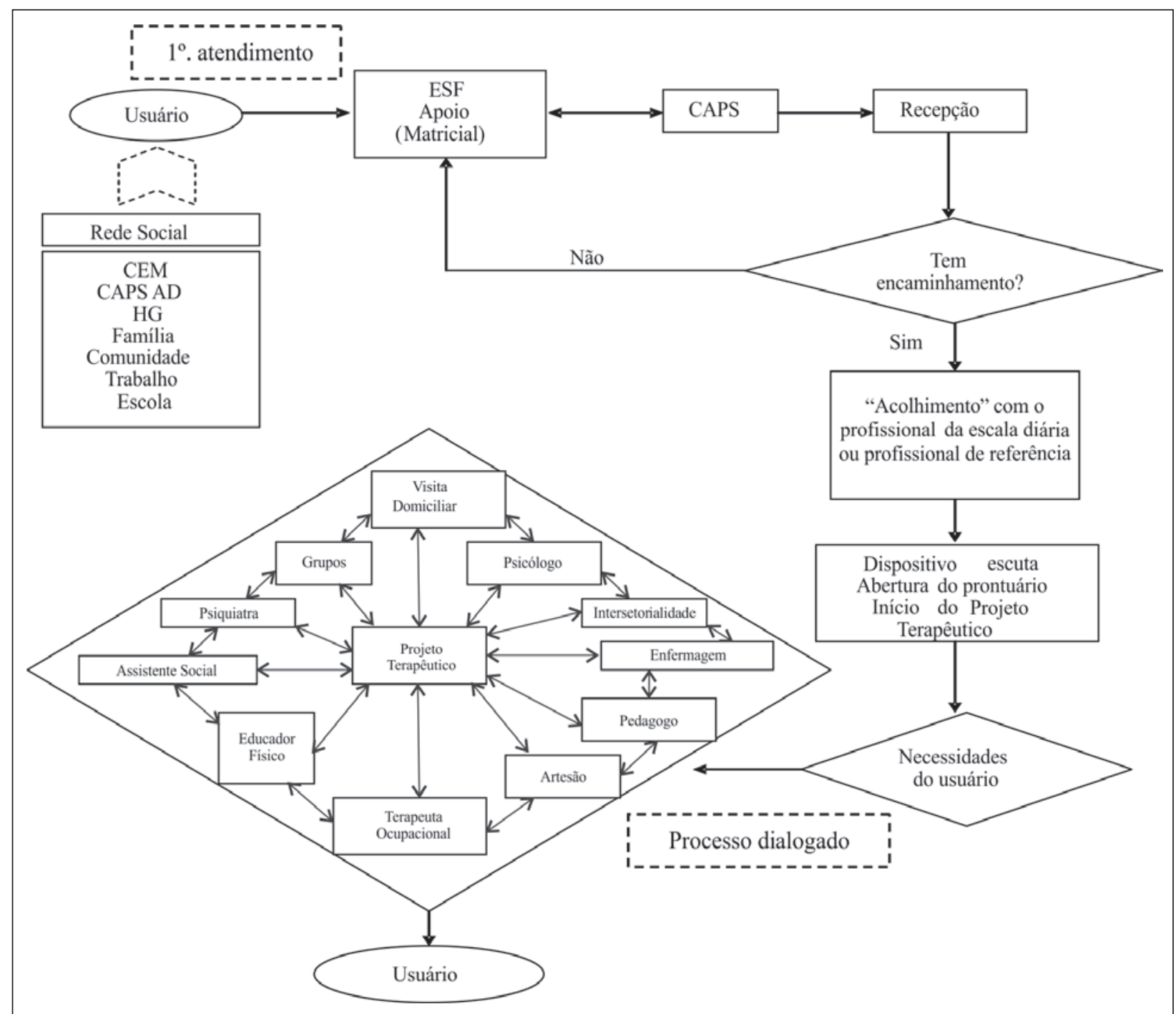

Figura 1 - Fluxograma analisador do CAPS Geral de Sobral-CE. Usuário que tem acesso pela primeira vez ao CAPS e a construção do seu projeto terapêutico

Esse fluxograma retrata as possibilidades de entrada do usuário no serviço até sua possível saída. Em Sobral, a Estratégia Saúde da Família (ESF) funciona como porta de entrada para a Rede Integrada de Saúde Mental do município, como afirmam os trabalhadores: a rede de saúde mental [...] trabalha de maneira articulada com o ESF. Na realidade, a porta de entrada é a ESF, o primeiro contato é lá. Aí, nós temos os trabalhos de ação matricial, que é o psiquiatra [...] com outros profissionais [...] que fazem a ação de matriciamento e que atendem junto com os profissionais da ESF, lá na unidade de saúde (Grupo I).

Porém, o indivíduo que chega à Unidade Básica de Saúde (UBASF) pode ser proveniente de várias outras instâncias, as quais seriam as várias possibilidades de locais de encaminhamento do usuário de saúde mental para o ESF, como: fábricas, comunidade, Hospital Geral (HG), Centro de Especialidades Médicas (CEM), CAPS AD, Família e outros. 
Enquanto as redes sociais estão configuradas no próprio modo de vida das pessoas, a conformação dos fluxos de atendimento nos serviços de saúde está diretamente relacionada com essa rede de apoio no tocante a demanda e à vinculação. Portanto, a rede de cuidados de cada sujeito considera seus espaços de interação social, tais como: trabalho, lazer, relações afetivas, entre outros.

Após a chegada do usuário à ESF, ele é atendido pela equipe que o avaliará e identificará se ele tem ou não necessidade de cuidado em saúde mental. Se essa necessidade for confirmada, a partir desse momento, é marcada uma consulta na própria unidade de saúde, com a ESF e com os preceptores de saúde mental do município (apoio matricial). Estes, em conjunto, irão avaliar as verdadeiras necessidades do usuário (triagem), podendo encaminhá-lo ou não para o CAPS Geral. Caso se trate de um sofrimento psíquico ou de transtorno de saúde mental leve, esse usuário faz sua terapêutica e acompanhamento na própria UBASF.

Essa interpretação do fluxograma é confirmada pelas falas seguintes: lá na atenção primária, o enfermeiro e o médico [...] marcam primeiro para preceptoria, que é uma vez por mês. Aí o preceptor em conjunto com a equipe da ESF vão decidir se esse paciente tem demanda para ir pro CAPS ou se esse paciente não tem demanda para ir ao CAPS [...]. Ou, então, esse paciente tem uma demanda de saúde mental, mas pode ser feita na própria ESF. Isso é triar, é fazer o encaminhamento dentro da necessidade desse paciente (Grupo I).

Como evidencia esse contexto, CAPS e ESF devem estar interconectados num circuito interinstitucional integrado no SUS. Tal situação pode evitar a fragmentação dos atendimentos e ainda facilitar o planejamento de área de saúde distrital, sobretudo no concernente aos atendimentos domiciliares e às intervenções clínicas na rede pessoal significativa do usuário. ${ }^{13}$

A interconexão desses serviços se dá com o apoio matricial que se configura como um suporte técnico especializado ofertado a uma equipe interdisciplinar de saúde com vistas a ampliar seu campo de atuação e qualificar suas ações. Por propiciar maior consistência às intervenções em saúde em geral e em saúde mental em particular, o apoio matricial da saúde mental é potente. Com base nas discussões clínicas conjuntas com as equipes ou mesmo intervenções conjuntas concretas (consultas, visitas domiciliares, entre outras), os profissionais de saúde mental podem contribuir para o aumento da capacidade resoluti- va das equipes, qualificando-as para uma atenção ampliada em saúde que contemple a totalidade da vida dos sujeitos. ${ }^{14}$

Nesse primeiro momento já se inicia a construção do projeto terapêutico desse usuário, mediante uma triagem desse indivíduo, com um levantamento da sua história de vida e suas queixas.

Depois dessa triagem, o usuário cujo perfil se enquadrar em CAPS é encaminhado para o devido centro. No CAPS, todo usuário passa pela recepção, que irá designá-lo para sua referida necessidade. Como se trata de usuários novatos no serviço, esses só serão orientados para o acolhimento se tiverem encaminhamento da ESF; do contrário, se for um encaminhamento de qualquer outra instância ou se não tiver encaminhamento, o usuário deverá procurar sua respectiva UBASF para se fazer a triagem, exceto em casos especiais como surtos psicóticos, ameaça de suicídio e outros.

De posse de um encaminhamento, ou mesmo sem ele, como acontece com os casos especiais, o usuário é dirigido para o acolhimento onde o profissional responsável adotará as seguintes providências: uma escuta acolhedora, a abertura do prontuário, o exame físico, uma complementação do histórico realizado pela equipe matricial, identificando as verdadeiras necessidades daquele usuário. A partir daí, inicia-se a construção do projeto terapêutico do usuário no CAPS. Conforme exposto: o projeto terapêutico é construído desde o primeiro momento que o cliente entra no serviço, através da porta de entrada, que a gente chama de acolhimento [...]. A gente já monta esse projeto mínimo e no decorrer do acompanhamento do paciente, esse projeto pode mudar ou não, se adequando ao aspecto do paciente naquele momento [...] tá discutindo esse projeto nas reuniões, se for necessário a gente modificar, a gente modifica (Grupo I).

Como parte do projeto terapêutico, e como etapa do conjunto do processo de trabalho que o serviço desencadeia na sua relação com o usuário, o acolhimento pode evidenciar as dinâmicas e os critérios de acessibilidades aos quais os usuários estão submetidos nas suas relações com o que os modelos de atenção pregam como verdadeiros campos de necessidades de saúde para si. ${ }^{15}$

Contudo, o acolhimento no CAPS não é compreendido, somente, como um dispositivo que facilita o acesso do usuário ao serviço de saúde; ele perpassa toda a terapêutica, por meio do diálogo, da escuta, da parceria existente entre trabalhador/ usuário/família. Ao mesmo tempo, favorece a construção do vínculo, da corresponsabilização e da autonomia. 
Mais do que um espaço de recepção, ou um ponto determinado de um fluxograma, o acolhimento constitui um dispositivo capaz de perpassar todo e qualquer espaço e momento de trabalho de um serviço de saúde. Para isso, o mesmo raciocínio parece valer também para a questão do vínculo e da responsabilização, basta que as tecnologias de conversação sejam desenvolvidas no sentido de uma ausculta sensível - assim permitirá em todos esses espaços e momentos a irrupção do outro, com suas variadas demandas - e de uma orientação assistencial voltada à integralidade do cuidado - com capacidade e agilidade de produzir algum tipo de resposta do serviço a essas demandas. ${ }^{16}$

Determinados profissionais, como terapeutas ocupacionais, psicólogos, enfermeiros e assistentes sociais, são incumbidos de realizar o acolhimento. Tal atividade possui aspectos de triagem, pois funciona com hora e objetivo determinado - garantir a acessibilidade - e é realizado por técnicos do serviço em local e turno específicos, reduzindo a concepção relacional de acolhimento, se delimitando a organização do serviço. Assim, observamos que diariamente os profissionais se dividem em escalas de serviços nos dois turnos, manhã e tarde, para a realização do acolhimento, ficando responsáveis em acolher as demandas que chegam ao CAPS. Desse modo, os usuários que acessam o serviço em busca de atendimento para os seus problemas de saúde, são recebidos pelo profissional destinado em realizar o acolhimento no processo de cuidar inicial, e este se torna o técnico de referência, ou seja, o profissional que acompanhará o caso e será responsável em levar a discussão para equipe multiprofissional. No sentido integral da abordagem terapêutica, cabe a todos os membros da equipe fazer o acompanhamento longitudinal do processo saúde/ doença/ intervenção de cada usuário numa perspectiva dialógica e resolutiva. ${ }^{14}$

Como podemos observar, os casos são discutidos por toda a equipe, num trabalho multidisciplinar. Isso pressupõe interação, parceria entre os trabalhadores envolvidos no processo de cuidar, conforme identificado nas falas a seguir: a gente, realmente, trabalha de forma interdisciplinar, multiprofissional de diversas categorias. A gente consegue, realmente, ter um entrosamento muito bom, com uma discussão bem leve e bem aberta dos casos [...] A equipe [...] tem uma abertura muito grande de tá discutindo os casos, de tá interagindo com os outros profissionais (Grupo II).

Como consta na literatura, a gestão dos recursos humanos em saúde deve pressupor que o cuidado é um produto produzido em ato vivo e no campo psicossocial decorre de ações multi e interdisciplinares. Para a efetiva participação dos trabalhadores na produção do cuidado a partir de dispositivos como o vínculo e o acolhimento da clientela, urge a operacionalização das propostas da política de desprecarização do trabalho em saúde com vistas à permanente e efetiva vinculação empregatícia no SUS. ${ }^{17}$

À medida que o trabalhador de saúde mental não é priorizado pelas ordenações públicas de organização do trabalho e de seus contratos, de forma a estabilizar o seu vínculo, a lógica de entrada e saída de alguns profissionais, no caso, o médico ou psiquiatra, parece ser a de mercado, no qual o espaço que ofereça melhores condições de trabalho será priorizado na contratação.

Esse fluxo comunicativo entre profissionais facilita a horizontalização do poder e a possibilidade de exercer diferentes papéis e funções relativas ao contexto interventivo multifacetado. Tratando-se de um trabalho em equipe, as diversas ações de saúde mental necessitam ser coordenadas entre elas numa coerência interna interdisciplinar entre saberes e fazeres. ${ }^{13}$

\section{Construção do projeto terapêutico compar- tilhado, integral e singular}

O projeto terapêutico é elaborado com base nas necessidades de saúde de cada usuário, não excluindo suas opiniões, seus sonhos, seu projeto de vida. Esse projeto é algo singular, uma interação democrática e horizontal entre trabalhador/ usuário/família. Por isso ele pode seguir vários caminhos, como o exposto: eu sempre dou opinião sobre o meu tratamento [...] ela não diz exatamente o que eu tenho que fazer, ela deixa que eu me expresse, dê as minhas opiniões (Grupo II). Realmente, qualquer acompanhamento e o projeto terapêutico nunca podem ser propostos de forma solitária pelo médico. A construção é com o cliente e com o familiar, porque eles têm que tá bem comprometidos (Grupo I).

De modo geral, as necessidades em saúde são traduzidas como as demandas de saúde, as quais vão além das carências dos sujeitos que procuram os serviços. No caso da saúde, o usuário de um serviço busca algo (as ações de saúde) que tem um valor de uso fundamental caracterizado como autorização para que sua saúde seja mantida ou restabelecida. Assim, propicia-se o acesso a algo com um valor de uso inestimável, pois tem como finalidade a manutenção da vida, e com autonomia para exercer seu modo de caminhar. ${ }^{18}$ 
Conforme percebemos, o profissional de referência possui um "leque de opções" para a elaboração do projeto terapêutico do usuário. Dessa maneira, ele pode encaminhá-lo para as opções mais eficazes para a terapêutica do sujeito. Como observamos no CAPS, não só o profissional de referência tem a liberdade de modificar esse projeto, como todos os profissionais que acompanham esse usuário, sempre tendo em vista as opiniões e preferências dos usuários de saúde. Tal processo ocorre de modo dialogado entre os sujeitos nas reuniões de equipe.

Então, o projeto terapêutico no CAPS Geral é uma espécie de rede na qual todos os pontos estão interligados. Pode ou não existir um fluxo contínuo entre eles, de acordo com a singularidade de cada projeto terapêutico e com um único propósito comum: o bem-estar desses usuários, mediante reabilitação psicossocial.

Tendo em vista a pluralidade de sujeitos envolvidos, tal situação requer formas de atuação que lhes sejam adequadas. Encontrar possibilidades singulares a cada pessoa, nas diferentes situações de suas vidas, pede a todo instante o olhar e a escuta que reconheçam as subjetividades. Dessa forma, a proximidade com a pessoa que sofre a experiência de transtorno mental coloca em confronto as diversas possibilidades interpretativas, interroga competências, pede sensibilidade do profissional. Pede, também, o entendimento de que o sofrer psíquico não pode ser visto como algo a ser eliminado ou combatido, mas como um caminho capaz de levar à redescoberta do real, da compreensão da experiência emocional de quem a vivencia. ${ }^{19}$

Portanto, a noção de projeto remete a um plano-ação, em desconstrução institucional, que engloba uma visão global da situação social existencial e de saúde mental do(s) usuário(s) e meios operacionais susceptíveis de responder à(s) sua(s) demanda(s). Esse plano-ação orienta, em termos gerais, as decisões e se configura como um "lançar para diante" práticas em invenção, preocupadas com a inserção social e a qualidade de vida do(s) usuário(s). ${ }^{13}$

No segundo fluxograma, a seguir, expomos a (re) construção do projeto terapêutico dos usuários já em acompanhamento no CAPS.

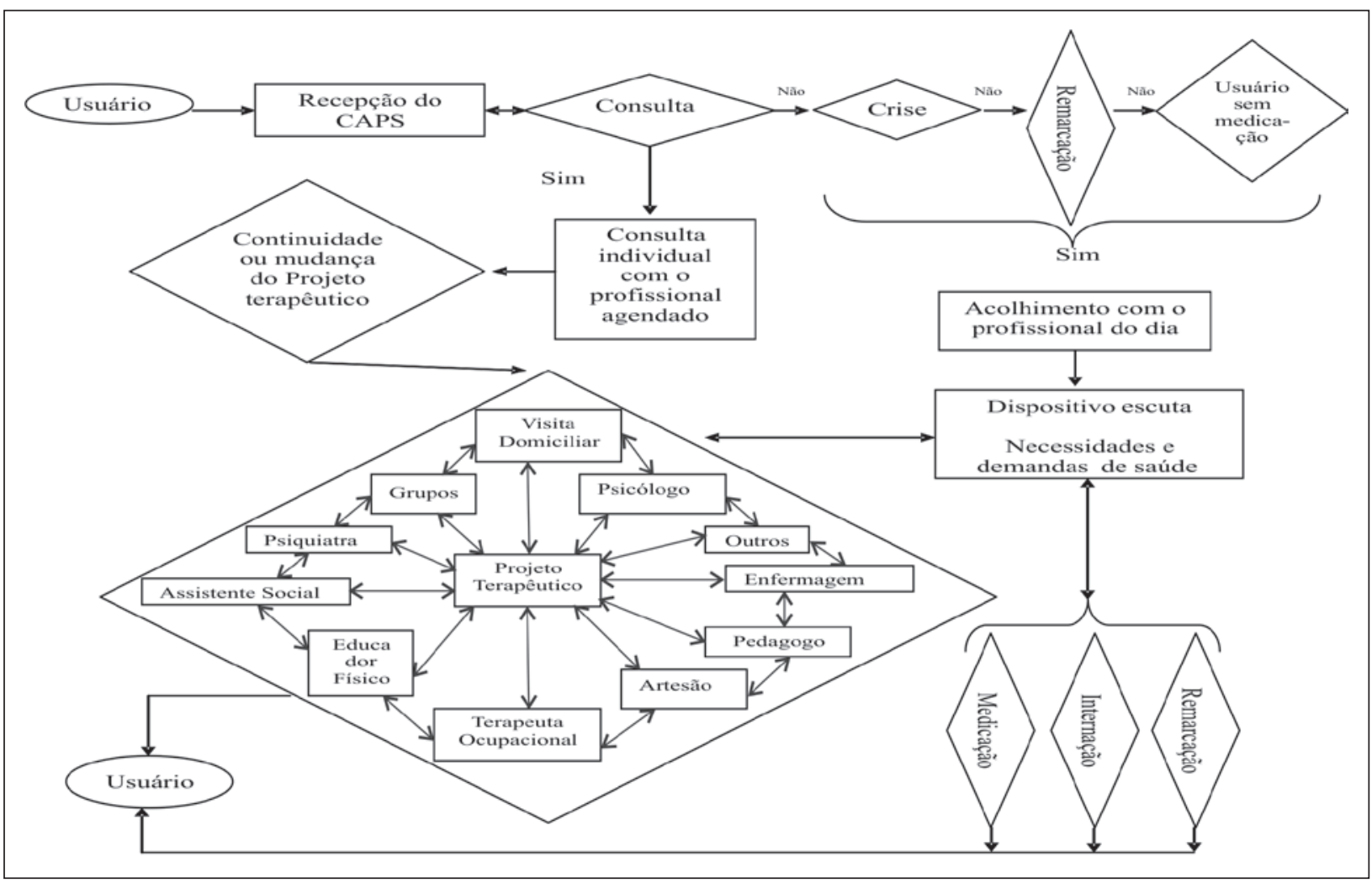

Figura 2 - Fluxograma analisador do CAPS Geral de Sobral-CE. Usuário que já faz tratamento no CAPS e a (re) construção do seu projeto terapêutico 
Como mostra esta figura, o usuário que já é atendido pelo serviço procura também a recepção do CAPS na tentativa da resolubilidade das suas necessidades. Estas podem ser abordadas em uma consulta previamente agendada, na qual o usuário ou familiar será atendido por um profissional do serviço. O referido profissional dará continuidade ao projeto terapêutico construído pelos trabalhadores do CAPS ou poderá modificar esse projeto de acordo com as necessidades percebidas durante a consulta. Essa mudança ocorre em consonância com os encaminhamentos e as possibilidades existentes no cardápio do CAPS, ou seja, o projeto terapêutico é dinâmico, variando com as nuances dos aspectos biopsicossociais de cada usuário.

$\mathrm{O}$ atendimento pelo profissional de saúde que está no acolhimento é outra situação que a ser ressaltada. Tal possibilidade acontece geralmente nos casos de crise (surtos), remarcação de consulta e falta de medicação. O profissional do acolhimento realizará uma escuta acolhedora do usuário ou familiar que busca o serviço de saúde e identificará sua necessidade. Ele pode recomendar uma internação em leitos no hospital geral do município, a liberação de receitas com o psiquiatra do serviço, uma remarcação de consulta, ou modificar o projeto terapêutico desse usuário acrescentando outras possibilidades do cardápio terapêutico, por exemplo: grupos dos quais o usuário ainda não participava, atendimentos individualizados com outros profissionais, atividades extramuros, como a escola de música e a massoterapia, e outros. Esse profissional responsável pelo acolhimento é bem representado na fala a seguir: [...] são todos os profissionais de nível superior [...]. Cada dia fica um trabalhador de referência pra atender tanto esses casos como aqueles casos de pessoas que desestabilizaram, ou deixaram de tomar a medicação, ou tão apresentando alteração no quadro psicopatológico (Grupo I).

Essa dinamicidade e a valorização dos aspectos singulares de cada usuário são observadas nas seguintes falas: então, cada caso, na realidade, vai sendo construído mediante a necessidade do usuário. Porque, a gente busca não tá trabalhando com o projeto camisa de força [...], tipo assim, coloca aquele projeto terapêutico que não se modifica com o tempo; pelo contrário, a gente tá sempre flexibilizando mediante as necessidades dos usuários, os interesses deles e o que o próprio trabalhador de saúde tá percebendo e vai sugerindo mudanças para aquele usuário (Grupo I). O projeto terapêutico, ele começa a ser construído quando o usuário passa pelo PSF [matriciamento] e ele é modificado constantemente pela sua trajetória aqui no CAPS, de acordo com as necessidades do usuário (Grupo focal).
As falas retratam a flexibilização desse projeto e sua construção baseada nos aspectos e possibilidades de vida de cada usuário. Utilizam-se todas as possibilidades do cardápio terapêutico, desde consulta individual até atividades extramuros, na tentativa de reabilitar o indivíduo.

Nessa ótica, a reabilitação psicossocial configura-se como conjunto de estratégias direcionadas a aumentar as possibilidades de trocas, a valorização das subjetividades e a proporcionar contratualidade e solidariedade, ultrapassando, assim, a mera implantação das redes de serviço. ${ }^{19}$

Nesse contexto, o projeto terapêutico é compreendido como um condensado das ações em saúde; nele se inscreve a concepção de ser humano que subjaz à prática e às tecnologias que foram ou são desenvolvidas para alcançar os objetivos de cuidar, ampliar o entendimento e a apropriação do processo saúde-doença pelo portador de transtornos mentais e a melhoria da sua qualidade de vida. ${ }^{20}$

Outro aspecto importante na construção do projeto terapêutico é o seu alicerce nas tecnologias leves em saúde (acolhimento, vínculo, corresponsabilização e autonomia), que favorecem a adesão do usuário/família ao tratamento. Vejamos as falas: o vínculo é a base de tudo, é a partir da vinculação de você acreditar, querer vincular com aquela pessoa ou proposta é que você vai tá aderindo a esse tratamento que a pessoa tá vivenciando (Grupo I). A gente tenta construir nesse projeto terapêutico algo que também se enquadre como projeto de vida, dá pra essas pessoas a capacidade de prover os sonhos. Tá empoderando. Por isso a importância de tá discutindo com as pessoas o tratamento, quais são seus sonhos, suas possibilidades e isso seria a questão de reabilitação psicossocial. Então, a gente tem uma articulação com a Secretaria de Cultura, onde as pessoas participam de shows, do teatro, utilizam a escola de música, utilizam a escola de comunicação, utilizam os espaços comunitários rompendo com o modelo asilar e segregador (Grupo focal).

As tecnologias leves são dispositivos fundamentais no cuidado em saúde mental, com ênfase na reabilitação psicossocial. Desde o início, elas facilitam a permanência e a adesão do usuário e da família ao tratamento. Para isto, o trabalhador atua por meio da boa recepção desses sujeitos, do diálogo, da escuta acolhedora, da formação de vínculos afetivos, do estabelecimento de parcerias e da valorização do projeto de vida desses indivíduos. O trabalhador também escuta seus sonhos, suas incapacidades, seus medos, numa interação horizontal e democrática entre usuário/ trabalhador/família. 
Essa interação induz a tomada de responsabilidade por esses sujeitos, isto é, propõe um direcionamento da atenção, levando em conta: a escuta, o acolhimento, a ética, a autonomia, o resgate da cidadania, a subjetivação, o respeito, a liberdade e a inclusão social, entre outros. É ao redor deste ideário e acordos comuns que profissionais com diferentes formações, com diferentes crenças e filiações teóricas, se reúnem e formam equipes multidisciplinares em conjunto com usuários/ famílias, no trabalho cotidiano dos serviços de saúde mental e no campo da atenção psicossocial. ${ }^{21}$

Dessa forma, a família é parte fundamental na terapêutica e convocá-la para assumir essa responsabilidade do cuidado com o usuário em conjunto com a equipe exige não apenas um redirecionamento das práticas, mas também um comprometimento e uma responsabilidade para a construção de um cuidado coletivo desses atores em promover e manter a autonomia do usuário, reconquistando sua cidadania e seu espaço na sociedade, por meio de uma responsabilização e de um cuidado coletivo. ${ }^{22}$ Essa compreensão é fortalecida pela fala: a corresponsabilização da família é fundamental, a gente sempre coloca isso, no tratamento de saúde mental é fundamental a presença desses três personagens: usuário/família/trabalhadores de saúde. Então, a gente busca essa corresponsabilização da família, a gente faz esse contato com a família mediante a abordagem individual, grupal e atenção domiciliária. Tentando conquistar, até mesmo, fazendo um trabalho pedagógico da família de se perceber como um agente terapêutico fundamental (Grupo I).

São inúmeras as possibilidades da corresponsabilização, por exemplo: a construção compartilhada do projeto terapêutico desloca a população usuária - indivíduo e família - do lugar de submetida (a um projeto definido pelos profissionais) para o lugar de aliada na construção de resoluções para os seus agravos de saúde. Nesse sentido, a prática busca a ampliação da capacidade de entendimento e a apropriação do controle do processo saúde-doença pelo usuário, a ampliação da sua capacidade de agenciar soluções no campo afetivo, material e social, e uma maior participação na vida política e jurídica. ${ }^{20}$

\section{CONSIDERAÇÕES FINAIS}

A pesquisa permitiu uma aproximação com a realidade do campo em estudo e, assim, percebemos que os projetos terapêuticos refletem as concepções sobre produção do cuidado formatadas com base nas ações em saúde. A partir dos fluxogramas descritores, ferramenta que possibilitou revelar desafios e avanços na (re) construção do projeto terapêutico dos usuários, observamos uma singularidade e dinamicidade no processo, uma vez que ocorre a utilização de tecnologias das relações e a participação multidisciplinar os trabalhadores do serviço.

Assim, os projetos terapêuticos são elaborados com base nas necessidades de saúde de cada usuário, levando em consideração seu modo de compreender a vida, suas subjetividades e singularidades, configurando-se numa interação democrática e horizontal entre os atores envolvidos no processo de cuidar (trabalhadores/usuário/ família), alicerçados pela utilização das tecnologias das relações que propõe novos fluxos e circuitos dentro do sistema, seguindo os movimentos dos usuários e a incorporação de novas tecnologias de trabalho e de gestão.

Outros avanços a serem destacados no processo dizem respeito à flexibilização e à participação, ou seja, configura-se numa (re) construção coletiva, a qual pode ser modificada conforme as necessidades. $O$ projeto terapêutico busca atender a demandas de saúde complexas e por isso conta com a equipe multidisciplinar, articulando saberes, práticas e conhecimento dos equipamentos comunitários, possibilitando a inserção do usuário em seu próprio meio.

Dessa forma, pensar no cuidado em saúde mental envolve pensar na integralidade do sujeito, do ambiente e das relações, pois o cuidado é um construto da cumplicidade de diversos atores apoiados em todos os contextos: sociais, econômicos, familiares, biológicos, psicológicos e culturais. E por isso comprometer-se com o cuidado em saúde é o desafio de ir além dos discursos para se aproximar de práticas transformadoras do modelo assistencial.

\section{REFERÊNCIAS}

1. Andrade RLP, Pedrão LJ. Algumas considerações sobre a utilização de modalidades terapêuticas não tradicionais pelo enfermeiro na assistência de enfermagem psiquiátrica. Rev Latino-am Enfermagem. 2005 Set-Out; 13(5):737-42.

2. Ministério da Saúde (BR). Saúde mental e o SUS: os centros de atenção psicossocial. Brasília (DF): MS; 2004.

3. Antunes SMMO, Queiroz MS. A configuração da reforma psiquiátrica em contexto local no Brasil: uma análise qualitativa. Cad Saúde Pública. 2007 Jan; 23(1):207-15. 
4. Ayres JRCM. Hermenêutica e humanização das práticas de saúde. Ciênc Saúde Coletiva. 2005 JulSet; 10(3):549-60.

5. Campos GWS, Amaral MA. A clínica ampliada e compartilhada, a gestão democrática e redes de atenção como referenciais teórico-operacionais para a reforma do hospital. Ciênc Saúde Coletiva. 2007 Jul-Ago; 12(4):849-59.

6. Campos GWS, Domitti AC. Apoio matricial e equipe de referência: uma metodologia para gestão do trabalho interdisciplinar em saúde. Cad Saúde Pública. 2001 Fev; 23(2):399-407.

7. Silva ALA, Fonseca RMGS. Processo de trabalho em saúde mental e o campo psicossocial. Rev Latino-am Enfermagem. 2005 Mai-Jun; 132(3):441-9.

8. Minayo MCS. O desafio do conhecimento: pesquisa qualitativa em saúde. $7^{\text {a }}$ ed. São Paulo (SP): Hucitec; 2006.

9. Minayo MCS. O desafio do conhecimento: pesquisa qualitativa em saúde. $11^{\text {a }}$ ed. São Paulo (SP): Hucitec; 2008.

10. Fontanella BJB, Ricas J, Turato ER. Amostragem por saturação em pesquisas qualitativas em saúde: contribuições teóricas. Cad Saúde Pública. 2008 Jan. 24(1):17-27.

11. Ministério da Saúde (BR). Resolução nº196/1996. Dispõe sobre pesquisa envolvendo seres humanos. Bioética 1996; 4(2 Supl):5-25.

12. Merhy EE. Em busca do tempo perdido: a micropolítica do trabalho vivo em saúde. In: Merhy EE, Onoko R, organizadores. Agir em saúde: um desafio para o público. São Paulo (SP): Hucitec; 2002.

13. Filho NGV, Nóbrega SM. A atenção psicossocial em saúde mental: contribuição teórica para o trabalho terapêutico em rede social. Est. Psicol. 2004 MaiAgo; 9(2):373-9.
14. Figueredo MD, Onoko RC. Saúde mental na atenção básica à saúde de Campinas, SP: uma rede ou um emaranhado?. Ciênc Saúde Coletiva. 2009 Jan-Fev; 14(1):129-38.

15. Franco TB, Bueno WS, Merhy EE. O acolhimento e os processos de trabalho em saúde: o caso de Betim, Minas Gerais, Brasil. Cad Saúde Pública. 1999 AbrJun; 15(2):345-53.

16. Ayres JRCM. Cuidado e reconstrução das práticas de saúde. Interface - Comunic., Saúde, Educação. 2004 Fev; 8(14):73-92.

17. Jorge MSB, Guimarães JMX, Nogueira MEF, Moreira TMM, Moraes APP. Gestão de recursos humanos nos Centros de Atenção Psicossocial no contexto da política de desprecarização do trabalho no Sistema Único de Saúde. Texto Contexto Enferm. 2007 JulSet; 16(3):417-25.

18. Merhy EE. Em busca de ferramentas analisadoras das tecnologias em saúde: a informação e o dia a dia de um serviço, interrogando e gerindo trabalho em saúde. In: Merhy EE, Onoko R. organizadores. Agir em saúde: um desafio para o público. São Paulo (SP): Hucitec 1997. p.113.

19. Pereira MAO. A reabilitação psicossocial no atendimento em saúde mental: estratégias em construção. Rev Latino-am Enfermagem. 2007 JulAgo; 15(4):658-64.

20. Aranha AL, Fonseca SRMGS. Os nexos entre concepção do processo saúde/doença mental e as tecnologias de cuidados. Rev Latino-am Enfermagem. 2003 Nov-Dez; 11(6):800-6.

21. Barros S, Oliveira MAF, Silva ALA. Práticas inovadoras para o cuidado em saúde. Rev Esc Enferm USP. 2007; 41(Esp):815-9.

22. Schank G, Olschowsky A. O Centro de Atenção Psicossocial e as estratégias para inserção da família. Rev Esc Enferm USP. 2008 Mar; 42(1):127-34. 